\title{
GERIATRIC TYPE 2 DIABETES; THE RISK FACTORS AND ASSOCIATIONS FOR MEDICATION NON-ADHERENCE.
}

\footnotetext{
1. MBBS, FCPS (Medicine) Associate Professor Department of Medicine Rawal Institute of Health Sciences Islamabad.

2. MBBS, FCPS (Medicine) Medical Specialist KRL Hospital Islamabad

3. MBBS, FCPS (Medicine)

Assistant Professor Dow University of Health Sciences Karachi.

4. MBBS, FCPS (Dermatology) Associate Professor /HOD Department of Dermatology Karachi Institute of Medical Sciences.

5. MBBS, FCPS (Medicine) Medical Specialist Airport Security Hospital Karachi.

6. MBBS, FCPS (Medicine) Professor

Department of Medicine Karachi Medical and Dental College.
}

Correspondence Address:

Dr. Nadia Shams

H No. 879, St No.79, Sector I-8/3,

Islamabad, Pakistan.

nadia_shams@yahoo.com

Article received on:

20/02/2019

Accepted for publication:

$17 / 05 / 2019$
Nadia Shams ${ }^{1}$, Sadia Amjad ${ }^{2}$, Naresh Kumar Seetlaniं ${ }^{3}$, Furquana Niaz ${ }^{4}$, Shazia Farhat ${ }^{5}$, Farhat Bashir ${ }^{6}$

ABSTRACT... Objectives: To determine medication adherence in geriatric type 2 diabetes cases, risk factors for non-adherence and association with functional dependence. Study Design: Descriptive cross sectional. Setting: Department of Medicine, RIHS Islamabad. Period: Sept. 2016 - Feb. 2017. Material \& Methods: 100 type 2 diabetes cases ( $>65$ years) included in group-A (geriatric group) and 100 gender matched type 2 diabetes cases ( $<65$ years) in group-B (non-geriatric group). Type 1 diabetes cases, critically ill and with incomplete medication record were excluded. Morisky Diabetes Questionnaire (MMAS-8) applied for medication adherence. Glycemic control, diabetes duration, co-morbids, treatment regime, poly-pharmacy, alternative medicine, functional status (Katz index) and visual morbidity assessed in both groups. Data analyzed by SPSS V-20 and Chi-square test applied with significant $p<0.05$. Results: Mean age was $71.43+5.58$ years (group-A) vs. $49.28+6.57$ years (group-B). Mean diabetes duration was $9.61+8$ years (group-A) vs. $7.4+4.9$ years (group B). Functional status was independent in $53 \%$ (group-A) vs. $86 \%$ (group-B), significantly dependent $40 \%$ (group-A) vs. $11 \%$ (group-B) and dependent $7 \%$ (group-A) vs. 3\% (group-B). High adherence in 3\% (group-A) vs. 10\%(group B); medium 24\%(group-A) vs. 32\%(group-B) and low 73\%(group-A) vs. 58\% (group B). Nonadherence in $73 \%$ (group-A) vs. 58\%(group-B). Poly-pharmacy, co-morbids, combination anti-diabetes regimes, visual morbidity, physical dependence and poor glycemic control was frequent in geriatric diabetes cases $(p<0.05)$. Conclusions: Medication adherence has pivotal role to attain target glycemic control. Higher medication non-adherence in geriatric diabetes cases needs to be addressed. Counseling sessions supported by literature in local language and addressing the identified risk factors may improve medication adherence in geriatric diabetes cases, hence improved glycemic control and morbidity.

Key words: Diabetes Mellitus, Medication Adherence, Geriatric Diabetes, Glycemic Control, Katz Index. MMAS-8 Score, Poly-pharmacy.

Article Citation: Shams N, Amjad S, Seetlani NK, Niaz F, Farhat S, Bashir F. Geriatric Type 2 diabetes; the risk factors and associations for medication non-adherence. Professional Med J 2020; 27(2):260-267.

DOI: 10.29309/TPMJ/2020.27.2.3300

\section{INTRODUCTION}

With the improved health care and increased life expectancy, there is rise in geriatric diabetes population. In Pakistan average life expectancy is 62 years and approximately four percent of population falls in geriatric age group. ${ }^{1}$ During last few decades, there has been persistent rise in diabetes all over the world. The global burden of diabetes has been reported by IDF Diabetes Atlas 2013 to be 382 million, with the expected figures of 592 million by $2035 .^{2}$ The estimated burden of diabetes in Pakistan is 6.9 million that is expected to rise by 2025 to 11.5 million. $^{3}$
Themanagementofdiabetesneedsmultidirectional approach including life style changes, dietary modification, selection of appropriate treatment regime, along with prevention and treatment of complications. The managing team should aim to ensure compliance to all these aspects to reduce the mortality and morbidity in diabetes cases. ${ }^{4}$ Though the terms compliance and adherence have been synonymously used, recent studies suggest adherence to be used as a preferred term. Adherence to medication is defined as extent to which patient takes the medications that has been prescribed by his physician or health

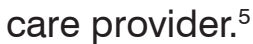


The data from various studies shows regional variation in level of drug adherence. ${ }^{6}$ The socioeconomic factors, knowledge and insight of disease, education status, physical morbidity, memory loss, psychological issues, financial constraints and lack of family support has an impact on drug adherence in geriatric diabetes cases. The age related cognitive decline also contributes to non-adherence. ${ }^{7}$ The knowledge score in patients with diabetes declines by $3 \%$ with every ten years rise in age according to study conducted by West JD. ${ }^{8}$ The management of geriatric patients with diabetes cases imposes new challenges in background of long standing disease with complications, cognitive impairment, dementia, physical and financial dependence. The psychological counseling has been recommended for diabetes cases and his care taker. ${ }^{9}$ Guidelines suggest same targets and goals for geriatric and non-geriatric diabetes mellitus cases, yet approach to management plan needs to be individualized particularly in geriatric patients with diabetes. ${ }^{10}$

Multiple regional studies have been conducted on various aspects of diabetes and its complications, however few have focused on geriatric population. The results of this study will be helpful to get an estimate of drug non-adherence in our geriatric diabetes patients and study the associated risk factors. Addressing these risk factors may help us plan and improvise measures to improve dug adherence and hence achieve target glycemic control in our geriatric diabetes mellitus patients.

\section{MATERIALS AND METHODS}

This descriptive cross sectional study was conducted at Rawal Institute of Health Sciences Islamabad from Sept. 2016 to Feb. 2017 after ethical approval from institutional committee. Total 200 cases were selected from outdoor diabetes clinic, dept. of Medicine after informed consent by convenience sampling. One hundred type 2 diabetes cases (age $\geq 65$ years) selected in group $A$ (geriatric group) and 100 cases of type 2 diabetes (age < 65 years) in group B (nongeriatric group). Informed consent was obtained from each patient. Type 1 diabetes cases, those on diet control alone, those with absent or incomplete record of prescribed medications, critically ill cases and those with mental or physical morbidity hampering their capability to understand or answer the questionnaire were excluded.

Demographic details, duration of diabetes, antidiabetes medication regime, other modes of therapy (i.e. Hikmat, herbal and homeopathic medicine) was documented. Glycosylated hemoglobin, i.e. HbA1c was advised and satisfactory glycemic control labeled at $\mathrm{HbA1c}$ $\leq 7 \%$ as recommended by American Diabetes Association (ADA). ${ }^{11}$

Morisky Diabetes Questionnaire (MMAS-8 score) used to assess medication adherence. The total score obtained by adding points for eight questions and ranges from 0-8 points. Patients were categorized as having low (score <6), medium (score $=6$ and $<8$ ) or high adherence (score = 8) (Table-II) with final outcome as adherent (score $\geq 6$ ) or non-adherent (score < 6 points). ${ }^{12,13}$

The functional status was assessed by Katz index comprising of 6 questions. Response to each question is either dependent (score 1) or independent (score 0 ). The cumulative score ranges between 0 and 6 points with final outcome as significant dependence (0-2 points), partial dependence (3-4 points) or independence (5-6 points).

SPSS version 17 was used for data analysis. Frequencies and percentages calculated for descriptive variables (i.e. gender, glycemic control, poly-pharmacy \& functional status). Mean and standard deviation calculated for quantitative variables (i.e. age \& duration of diabetes). Chisquare test applied to study association of drug adherence with glycemic control and other risk factors. $P$-value $<0.05$ considered as statistically significant.

\section{RESULTS}

Among 200 cases of type 2 diabetes, mean age was $56.6 \pm 10.6(36-86)$ years; $71.43 \pm 5.58$ years in geriatric (group A) Vs. $49.28 \pm 6.57$ years 
among non-geriatric (group B) diabetes cases $(p<0.0005)$. Mean duration of diabetes was 9.61 \pm 8 years (group A) vs. $7.4 \pm 4.9$ years (group B) $(p=0.005)$. Glycemic control was satisfactory in $10(10 \%)$ (group A) vs. $24(24 \%)$ (group B) $(p=0.008)$ (Table-l).

Mode of therapy was oral hypoglycaemics in $67(67 \%)$ (group A) Vs. 82(82\%) (group B), insulin in $7(7 \%)$ (group A) Vs. $14(14 \%)$ (group B) and combination therapy in $26(26 \%)$ (group A) Vs. $4(4 \%)$ (group B) $(p<0.0005)$. Poly-pharmacy was found in $57(57 \%)$ (group A) Vs. 37(37\%) (group B) $(p=0.005)$. Other modes of therapy were found in 26(26\%) (group A) Vs. 33(33\%) (group B) $(p=0.278)$

Medication adherence as per MMAS-8 score was high in 3(3\%) (group A) Vs. 10(10\%) (group B); medium in 24(24\%) (group A) Vs. 32(32\%) (group $B)$ and low in $73(73 \%)$ (group A) Vs. 58(58\%) (group B) $(p=0.036)$. Non-Adherence (i.e MMAS8 score $<6$ ) labeled in $73(73 \%)$ (group A) Vs. $58(58 \%)$ (group B) $(p=0.026)$.

$58 \%$ of geriatric diabetes cases said they sometimes forget to take medicines vs. $45 \%$ nongeriatric. $60 \%$ geriatric diabetes cases forgot to take medicines during the last 2 weeks period vs. $47 \%$ non-geriatric. $40 \%$ geriatric diabetes cases used to stop medications when they feel unhealthy vs. $28 \%$ non-geriatric. $52 \%$ geriatric diabetes cases forgot to take medicines when they leave home vs. $40 \%$ non-geriatric. $85 \%$ geriatric diabetes cases took medicines the day before hospital visit vs. $79 \%$ non-geriatric. $32 \%$ geriatric diabetes cases stopped medication on improvement of symptoms vs. $23 \%$ non-geriatric. $75 \%$ geriatric diabetes cases felt hassled of their treatment plan vs. $81 \%$ non-geriatric (Table-II).

Katz index based functional status

Functional status according to Katz index was independent in 53\% (group-A) vs. 86\% (group-B), significantly dependent $40 \%$ (group-A) vs. $11 \%$ (group-B) and dependent 7\% (group-A) vs. 3\% (group-B).

The geriatric diabetes cases had increased frequency of poor glycemic control, polypharmacy, co-morbid diseases, combination anti-diabetes therapy regimes, visual morbidity and physical dependence as compared to nongeriatric diabetes cases $(p<0.05)$. However there was no significant difference in use of other modes of therapy between geriatric and nongeriatric diabetes cases $(p>0.05)$.

Table-I Presenting comparison of demographic features and risk factors for non-adherence between geriatric and non-geriatric groups of type 2 diabetes cases $(n=200)$.

\begin{tabular}{|c|c|c|c|c|}
\hline Variables & $\begin{array}{c}\text { Among All } \\
n=200\end{array}$ & $\begin{array}{c}\text { Geriatric } \\
n=100\end{array}$ & $\begin{array}{c}\text { Non-Geriatric } \\
n=100\end{array}$ & P-Value \\
\hline $\begin{array}{l}\text { Male } \\
\text { Female }\end{array}$ & $\begin{array}{c}48(24 \%) \\
152(76 \%)\end{array}$ & $\begin{array}{l}25(25 \%) \\
75(75 \%)\end{array}$ & $\begin{array}{l}23(23 \%) \\
77(77 \%)\end{array}$ & 0.741 \\
\hline $\begin{array}{l}\text { Anti-diabetes Therapy } \\
\text { Oral hypoglycaemics } \\
\text { Insulin } \\
\text { Combination therapy }\end{array}$ & $\begin{array}{c}149(74.5 \%) \\
21(10.5 \%) \\
30(15 \%)\end{array}$ & $\begin{array}{c}67(67 \%) \\
7(7 \%) \\
26(26 \%)\end{array}$ & $\begin{array}{c}82(82 \%) \\
14(14 \%) \\
4(4 \%)\end{array}$ & $<0.001$ \\
\hline Other modes of therapy & $59(29.5 \%)$ & $26(26 \%)$ & $33(33 \%)$ & 0.278 \\
\hline Poor glycemic Control & $166(83 \%)$ & $90(90 \%)$ & $76(76 \%)$ & 0.008 \\
\hline Comorbid conditions & $105(52.5 \%)$ & $63(63 \%)$ & $42(42 \%)$ & 0.003 \\
\hline
\end{tabular}

Table-I. Risk factors among geriatric \& non-geriatric diabetes cases. 


\begin{tabular}{|c|c|c|c|}
\hline \multicolumn{2}{|l|}{ MMAS-8 Questions } & $\begin{array}{c}\text { Geriatric } \\
n=100\end{array}$ & $\begin{array}{c}\text { Non-Geriatric } \\
n=100\end{array}$ \\
\hline \multicolumn{2}{|l|}{ 1. Forgets to take medicines sometimes } & $58 \%$ & $45 \%$ \\
\hline \multicolumn{2}{|c|}{ 3. Stops medicines when feels unhealthy after taking medicines } & $40 \%$ & $28 \%$ \\
\hline \multicolumn{2}{|l|}{ 4. Forgets to take medicines while leaves home } & $52 \%$ & $40 \%$ \\
\hline \multicolumn{2}{|l|}{ 6. Stops medicines when feels healthy } & $32 \%$ & $23 \%$ \\
\hline \multicolumn{2}{|l|}{ 7. Feeling hassled about sticking to treatment plan } & $75 \%$ & $81 \%$ \\
\hline \multicolumn{2}{|l|}{$\begin{array}{ll}\text { 1. Difficulty in remembering to take medicines } \\
\text { Never/rarely } & \text { (4) } \\
\text { Once in a while } & (3) \\
\text { Sometimes } & (2) \\
\text { Usually } & (1) \\
\text { All the time } & (0) \\
\text { (Divide the score by } 4 \text { ) }\end{array}$} & $\begin{array}{c}15 \% \\
45 \% \\
10 \% \\
7 \% \\
0 \%\end{array}$ & $\begin{array}{l}39 \% \\
31 \% \\
11 \% \\
2 \% \\
0 \%\end{array}$ \\
\hline \multicolumn{4}{|c|}{ Table-II. Response to MMAS-8 questions in geriatric vs. non-geriatric type 2 diabetes cases $(n=200)$. } \\
\hline $\begin{array}{l}\text { Functional status among adherent and non- } \\
\text { adherent diabetes mellitus cases }\end{array}$ & $\begin{array}{c}\text { Geriatric } \\
n=100\end{array}$ & $\begin{array}{c}\text { Non-Geriatric } \\
n=100\end{array}$ & $\begin{array}{c}\mathrm{p}- \\
\text { value }\end{array}$ \\
\hline Adherent & $\mathrm{n}=27$ & $\mathrm{n}=42$ & \\
\hline $\begin{array}{l}\text { Functional status(Katz score) } \\
\text { Dependent(0-2) } \\
\text { Significant dependence(3-4) } \\
\text { Independent(5-6) }\end{array}$ & $\begin{array}{c}2(7.4 \%) \\
8(29.6 \%) \\
17(63 \%)\end{array}$ & $\begin{array}{l}1(2.4 \%) \\
2(4.8 \%) \\
39(93 \%)\end{array}$ & 0.008 \\
\hline
\end{tabular}

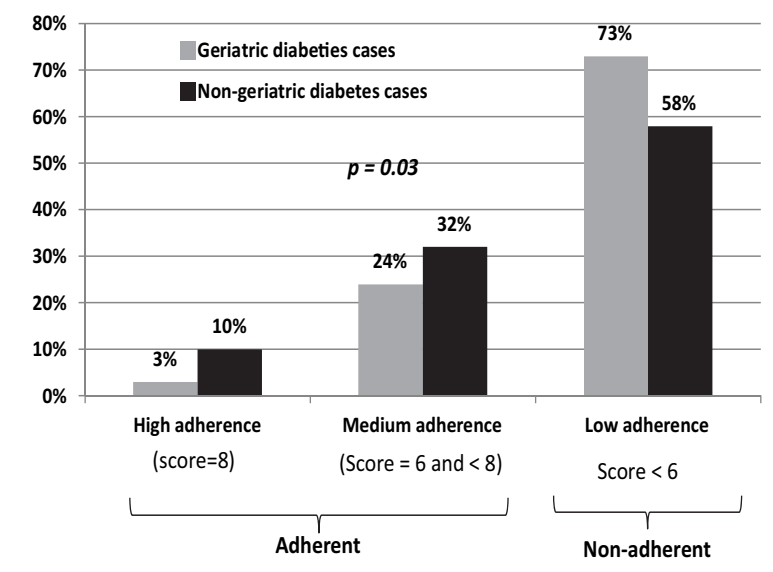

Figure-1. Bar graph presentation of levels of adherence as per MMAS-8 score in geriatric vs. non-geriatric diabetes cases $(n=200)$.

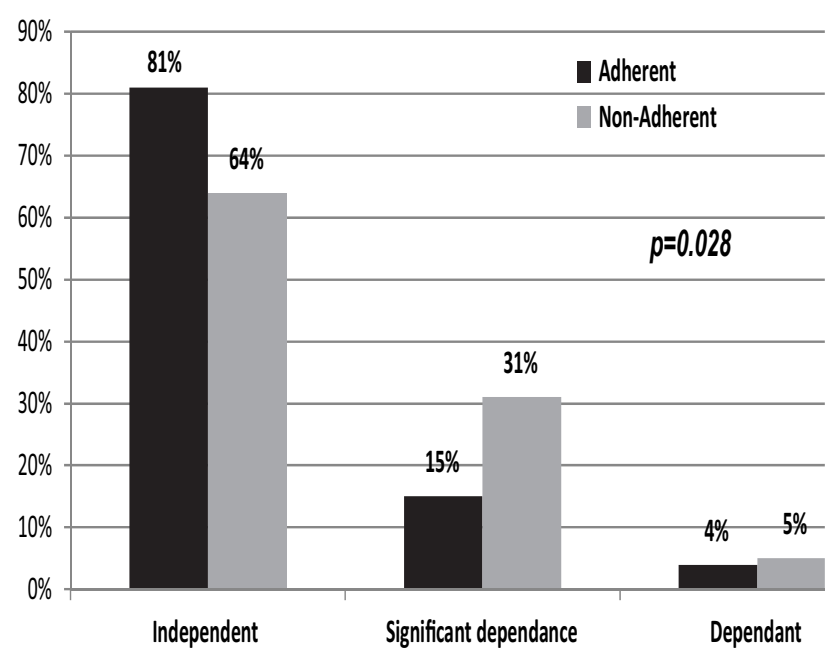




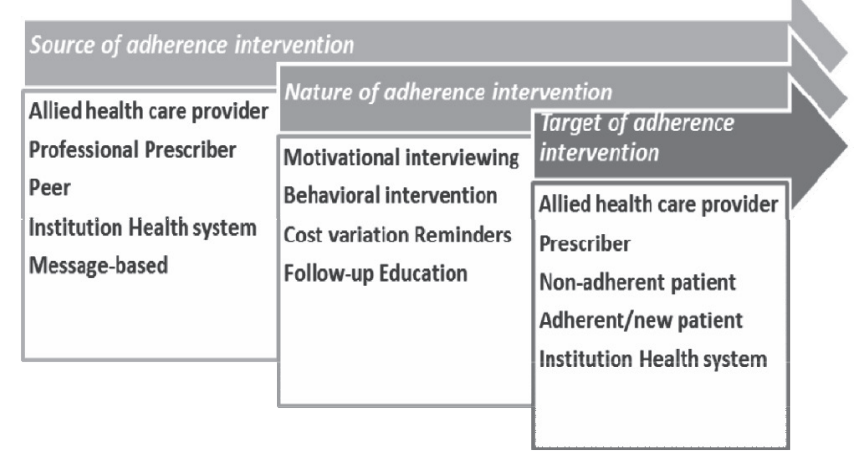

Figure-2. Figure summarizing various levels of intervention required to improve drug adherence; (adapted from Cochrane database 2005) [34].

\section{DISCUSSION}

There has been a persistent rise in global burden of diabetes despite of advancement in health care facilities. ${ }^{12}$ Contributory factors are sedentary life style, dietary pattern and rapid urbanization. Along with prolonged life expectancy, there has been rise in the geriatric population with chronic illnesses like diabetes, hypertension and ischemic heart disease. Geriatric diabetes cases need particular targeted measures to improve their quality of life. ${ }^{13}$

It has been observed that long standing diabetes (i.e.>10 years) has been associated with significantly high target organ damage including retinopathy, nephropathy, diabetic foot, cardiac and cerebrovascular events. ${ }^{14}$ In current study, mean age in geriatric group was 71 years having mean duration of diabetes 9.6 years, however non-geriatric group had mean age 49 years with 7 years mean duration of diabetes. Hence, geriatric diabetes patient having prolonged duration of diabetes are prone to diabetes related complications.

Literature suggests that, among geriatric diabetes cases fasting blood sugar levels raise by $1-2 \%$ per decade, however the post prandial levels raise by $15 \mathrm{mg} \%$ per decade. Hence monitoring of only fasting levels may underestimate the glycemic control. It is recommended that in addition to home monitoring, opportunistic screening may be used in geriatric diabetes cases i.e. blood sugars should be checked while performing other routine tests. ${ }^{7}$ In current study, geriatric group had poor glycemic control, i.e. $10 \%$ geriatric diabetes cases had satisfactory $\mathrm{HbA} 1 \mathrm{c}$ levels as compared to $24 \%$ non-geriatric diabetes cases. Shams et al found satisfactory glycemic control among $25 \%$ diabetes cases in Karachi based study. ${ }^{15}$ We may conclude that geriatric diabetes cases have comparatively poor glycemic control and hence are at high risk for diabetes complications.

Most of our cases were taking oral hypoglycaemics (74\%) with insulin therapy among few (10.9\%). This reflects the social norms and patient's preference for oral hypoglycaemics over insulin therapy. Also the geriatric group had higher use of combination therapy i.e. oral and insulin therapy combination (10\%) as compared to non-geriatric group (4\%). Premixed insulin used in Pakistan is effective, well tolerated, with good safety profile. According to South Asian Consensus guideline for management of Geriatric Hyperglycemia ${ }^{16}$, geriatric diabetes cases require lesser dose of insulin (0.1-2 units/kg/day) with weekly dose adjustment. Hence there is need to create awareness among health care providers to follow the geriatric guidelines as per indication.

Poly-pharmacy (i.e. use of $>3$ medications) was significantly more in geriatric diabetes cases $(57 \%)$ as compared to non-geriatric diabetes cases (33\%). Possible reasons could be the prolonged duration of diabetes in geriatric group imposing need for multiple medications for better glycemic control and associated co-morbids and complications management. Pasina $L$ et al in an Italy based study found poly-pharmacy in 55-70\% non-adherent geriatric patients ${ }^{17}$ Authors suggest that excess medications should be withdrawn after the required duration to improve compliance to essential medications and reduce the drug interactions as well.

Medication adherence was assessed by 8 questions based Morisky (MMAS-8) Scale (TableII). Among geriatric diabetes cases $73 \%$ were nonadherent as compared to $58 \%$ of non-geriatric. In current study, over all adherence levels were low in both the groups. However, geriatric diabetes cases had significantly higher non-adherence 
as compared to non-geriatric (Figure-1). Similar results were observed by Pasina $L$ et al in an Italian study that found non-adherence in 55$70 \%$ geriatric diabetes cases. ${ }^{19}$ Also, Haynes RB et al suggested that $50 \%$ of patients with chronic illnesses don't take the prescribed medication. ${ }^{18}$

The individual questions from the MMAS-8 score showed that $58 \%$ of geriatric diabetes cases forgot to take medicines sometimes. The age related decline in cognitive function could explain this forgetfulness. ${ }^{7}$ Hence there is a need to take measures to overcome this forgetfulness in geriatric diabetes cases. Use of pill boxes, phone alarms or reminders, and supervision by a responsible family member may be helpful. ${ }^{19}$

Forty percent of geriatric diabetes cases said that they used to leave medications without consulting their doctor due to worsening of symptoms or side effects of medications. The diabetes related gastro paresis, drug interactions due to poly-pharmacy and inappropriate dosage and scheduling could be possible reasons. Patients should be guided to report to doctor in case of side effects or worsening of symptoms rather than stopping the medications till next scheduled visit. Also the physician should be careful while introducing any new medication with close monitoring of side effects to ensure good compliance. ${ }^{20}$ It is advisable to follow the shared decision for management plan, as per the concept of patient empowerment in endocrinology. ${ }^{21}$

Fifty two percent geriatric diabetes cases forgot to take medicines when they leave home. Hence, indicating that counseling is required for patients to carry not only the required dose while leaving home, bur few extra doses also. However, the tendency to leave medications on improvement of symptoms was thirty two percent among geriatric diabetes cases.

Quite a significant number of geriatric diabetes cases, i.e.79\% took medications the day before hospital visit. This indicates that the awareness of scheduled hospital visit leads to better compliance. Ostenberg et al suggested that "white coat adherence" may give a false estimate of drug adherence ${ }^{22}$ Authors suggest that the patients having poor compliance be scheduled for frequent visits. They may be guided to bring the used packs or pill boxes to monitor the missed doses. Significant number of geriatric diabetes cases (i.e. 75\%) felt hassled about the treatment plan. The underlying factors vary case to case. Poly pharmacy, frequent dosing, drug intolerance, treatment costs, side effects could be the associated factors. A Nigerian study ${ }^{23}$ found comparatively lower figure of $58 \%$ diabetes cases that felt hassled of treatment plan with possible reason of complexity of regime.

Katz index was used to assess the functional status (Table-III). This status assesses the routine daily activity level rather than the advanced and fine skills. However, in geriatric diabetes cases the basic functional status in terms of self-care, personal hygiene, and routine daily activity bears importance. Almost $2 / 3^{\text {rd }}$ of diabetes cases were independent and $1 / 3^{\text {rd }}$ dependent. The geriatric diabetes cases were significantly more dependent $(47 \%)$ as compared to non-geriatric (14\%). Blaum CS et al found comparatively lower figure of low functional status (i.e. 28\%) among elderly diabetes cases bearing significant association with heart disease and mortality ${ }^{24} \mathrm{Li}$ $\mathrm{CL}$ et al found significant association between functional decline and mortality in older adults. ${ }^{25}$

Blaum $\mathrm{C}$ et al found $22 \%$ older diabetes cases with health status making diabetes self-management difficult or limited ${ }^{26}$ Chiu CJ et al found a consistent progress in disability in elderly diabetes cases over time..$^{27}$ Elsawy B et al suggested that geriatric assessment should include multidisciplinary assessment for functional ability, physical health, mental health, cognition, social circumstances; and extensive review of prescriptions, over the counter drugs, vitamins and herbal products. ${ }^{28}$

Certain limitations of the study include the sampling technique by convenience sampling and lack of randomization. Authors recommend that data of current study should be interpreted carefully and recommend future regional studies with improved sample size and multicenter selection of patients. 
Though multiple international studies have been conducted on functional status among geriatric diabetes cases and their associations, there is limited regional research data available in this context. Our geriatric population is facing issues of access to facility, financial constraints, nutritional deficiencies, social norms and poor quality of life. The results of current study will be valuable to estimate the associations and risks for non-adherence in geriatric diabetes cases. This may help us to implement measures to control and modify these risk factors for better adherence and hence improved glycemic control among our geriatric diabetes cases.

\section{CONCLUSIONS}

Increased life expectancy has led to rise in geriatric diabetes cases along with other chronic illnesses. Drug adherence has pivotal role in achieving the target glycemic control. The higher drug non-adherence in geriatric diabetes cases needs to be addressed, contributory factors being poly-pharmacy, combination anti-diabetes regimes, co-morbid conditions, visual morbidity and physical dependence. There is need to plan special counseling sessions supported by easy to interpret literature in local language and address the identified risk factors to improve drug adherence, hence leading to improved glycemic control and reduced morbidity in geriatric diabetes cases.

\section{Acknowledgements}

The authors would like to thank their patients to be a source of inspiration and their families for their support.

\section{Copyright@ 17 May, 2019.}

\section{REFERENCES}

1. Population reference bureau. The 2006 World Health Data Sheet. [Document on the Internet]. Washington DC; 2009 [cited 2009 May 28]. Available from: http:// www.prb.org/pdf06/ 06WorldDataSheet.pdf.

2. International diabetes federation. Diabetes atlas. $6^{\text {th }}$ ed. Brussels, Belgium: International Diabetes Federation: 2013.

3. International diabetes federation. Diabetes atlas. $3^{\text {rd }}$ ed. Brussels, Belgium: International Diabetes Federation: 2006.
4. Ho PM, Rumsfeld JS, Masoudi FA, et al. Effect of medication non-adherence on hospitalization and mortality among patients with diabetes mellitus. Arch Intern Med 2006; 166(17):1836-41.

5. Ho PM, Bryson CL, Rumsfeld JS. Medication adherence: Its importance in cardiovascular outcomes. Circulation 2009; 119:3028-35.

6. Safeer R, Keenan J. Health literacy: The gap between physicians and patients. Am Fam Physician 2005; 72:463-68.

7. Baruah MP, Kalra S, Unnikrishnan AG, Raza SA, Somasundaram N, John M, et al. Management of hyperglycemia in geriatric patients with diabetes mellitus: South Asian consensus guidelines. Indian J Endocr Metab 2011; 15:75-90.

8. West JD, Goldberg KL. Diabetes self-care knowledge among outpatients at a veterans affairs medical center. Am J Health Syst Pharm. 2002; 59(9):849-52.

9. Shamsi et al. Is there any relationship between medication compliance and affective temperaments in patients with type 2 diabetes? Journal of Diabetes \& Metabolic Disorders 2014; 13:96.

10. Chiniwala N, Jabbour S. Management of diabetes mellitus in the elderly. Current opinion in endocrinology. Diabetes \& Obesity 2011; 18(2):14852.

11. American diabetes association clinical practice recommendations: Executive summary: Standards of medical care in diabetes-2010. Diabetes Care 2010; 33(suppl.1):S4-5.

12. Frank B. Hu. Globalization of Diabetes. Diabetes Care Jun 2011; 34(6):1249-57.

13. Laiteerapong N, Karter AJ, Liu JY, et al. Correlates of quality of life in older adults with diabetes: The diabetes \& aging study. Diabetes Care. 2011; 34(8):1749-53.

14. Cea-Calvo L, Conthe P, Gomez-fernandez P, et al. Target organ damage and cardiovascular complications in patients with hypertension and type 2 diabetes in Spain: A cross sectional study. Cardiovasc Diabetol 2006; 3:23.

15. Shams $\mathrm{N}$, Osmani $\mathrm{MH}$. Newly diagnosed anemia in admitted diabetes cases, frequency, etiology and associated factors. J Coll Physicians Surg Pak. 2015; 25(4):242-6 
16. Baruah MP, Kalra S, Unnikrishnan AG, Raza SA, Somasundaram N, John $M$, et al. Management of hyperglycaemia in geriatric patients with diabetes mellitus: South Asian consensus guidelines. Indian J Endocr Metab 2011; 15:75-90

17. Pasina L, Brucato AL, Falcone C, et al. Medication nonadherence among elderly patients newly discharged and receiving poly-pharmacy. Drugs Aging. 2014; $31(4): 283-9$.

18. Haynes RB, McDonald HP, Garg AX. Helping patients follow prescribed treatment: Clinical applications. JAMA. 2002; 288(22):2880-3.

19. Jimmy B, Jose J. Patient medication adherence: Measures in daily practice. Oman Medical Journal. 2011; 26(3):155-59.

20. Tarn DM, Heritage J, Paterniti DA, Hays RD, et al. Physician communication when prescribing new medications. Arch Intern Med. 2006; 166(17):1855-62.

21. Kalra S, Unnikrishnan AG, Skovlund SE. Patient empowerment in endocrinology. Indian $\mathrm{J}$ Endocr Metab 2012; 16:1-3.

22. Osterberg L, Blaschke T. Adherence to medication. $\mathrm{N}$ Engl J Med. 2005; 353(5):487-97.
23. Jackson IL., Adibe MO, Okonta MJ, Ukwe CV. Diabetes technology \& therapeutics May 2015; 17(6):398-404.

24. Blaum CS, Ofstedal MB, Langa KM, Wray LA. Functional status and health outcomes in older Americans with diabetes mellitus. J Am Geriatr Soc. 2003; 51(6):745-53.

25. Li CL, Chang HY, Shyu Yl. The excess mortality risk of diabetes associated with functional decline in older adults: Results from a 7-year follow-up of a nationwide cohort in Taiwan. BMC Public Health. 2011; 11:953.

26. Blaum C, Cigolle CT, Boyd C, et al. Clinical complexity in middle-aged and older adults with diabetes: The health and retirement study. Med Care. 2010; 48(4):327-34.

27. Chiu CJ, Wray LA. Physical disability trajectories in older Americans with and without diabetes: The role of age, gender, race or ethnicity, and education. The Gerontologist. 2011 Feb 1;51(1):51-63.

28. Elsawy B, Higgins KE. The geriatric assessment. Am Fam Physician. 2011; 83(1):48-56.

\begin{tabular}{|c|c|c|c|}
\hline \multicolumn{4}{|c|}{ AUTHORSHIP AND CONTRIBUTION DECLARATION } \\
\hline Sr. \# & Author(s) Full Name & Contribution to the paper & Author(s) Signature \\
\hline 1 & Nadia Shams & & \\
\hline 2 & Sadia Amjad & & Sadia \\
\hline 3 & Naresh Kumar Seetlani & $\begin{array}{l}\text { equally to study design, data } \\
\text { collection and analysis, write }\end{array}$ & Naresi Kumu \\
\hline 4 & Furquana Niaz & $\begin{array}{l}\text { up, literature review and } \\
\text { referencing. }\end{array}$ & Furgan Nliaz \\
\hline 5 & Shazia Farhat & & Or Shazia. \\
\hline 6 & Farhat Bashir & & Farhat Bashir \\
\hline
\end{tabular}

